\title{
Survey of dialysis therapy during the Great East Japan Earthquake Disaster and recommendations for dialysis therapy preparation in case of future disasters
}

Ikuto Masakane ${ }^{1,2,3,4^{*}}$, Toshio Akatsuka ${ }^{1,3}$, Tomoyuki Yamakawa ${ }^{1,3,5}$, Yoshiharu Tsubakihara ${ }^{2}$, Ryoich Ando ${ }^{3}$, Tadao Akizawa ${ }^{1,5}$, Jun Minakuchi ${ }^{1}$ and Kosaku Nitta ${ }^{1}$

\begin{abstract}
The survey of dialysis therapy during the Great East Japan Earthquake Disaster (GEJED) highlighted the vulnerability of chronic dialysis therapy and dialysis patients to disasters. To minimize negative effects on patients on chronic maintenance dialysis during large-scale disasters that may occur in the future, it is important to promote the self-help efforts of dialysis facilities and to develop mutual assistance systems within local communities. Each dialysis facility has to take comprehensive disaster managements, including vibration control of large machinery, the use of flexible tubes, securing patient beds, and un-securing stand-type bedside consoles. Local governments should plan in advance how to support chronic dialysis therapy in their areas and how to assign roles among themselves when dealing with a large number of patients with acute kidney injury during long-term disruption of lifelines including electricity, water supply, and fuel. Dialysis patients are likely to develop cardiovascular events in times of disaster because of physical and psychological stress. Dialysis patients should understand in advance the key points of self-care in times of disaster and the availability of dialysis therapy in remote locations. It is also important to provide appropriate antihypertensive treatment to patients.
\end{abstract}

Abbreviations: AKI, Acute kidney failure; APD, Automated peritoneal dialysis; CAPD, Continuous ambulatory peritoneal dialysis; GEJED, The Great East Japan Earthquake Disaster; GHAED, The Great Hanshin-Awaji Earthquake Disaster; IAEA, The International Atomic Energy Agency; JACE, Japan Association for Clinical Engineers; JADP, Japanese Association of Dialysis Physicians; JSDT, Japanese Society for Dialysis Therapy; JSN, Japanese Society of Nephrology; M, Magnitude; MCA, Multi-channel access; PD, Peritoneal dialysis; RO, Reverse osmosis; SPEEDI, The System for Prediction of Environmental Emergency Dose Information; WG, Working group

\section{Introduction}

The largest earthquake in recorded history in Japan with a magnitude (M) of 9.0, which was centered off the Pacific coast of Tohoku, hit the Tohoku region and all of eastern Japan from Hokkaido to the Kanto region at 14:46 on 11 March 2011. The subsequent enormous tsunami caused by the earthquake struck the coast of

\footnotetext{
* Correspondence: imasakan.aipod@seieig.or.jp

'Working Group for Survey of Dialysis Therapy during the Great East Japan Earthquake Disaster, Japanese Society for Dialysis Therapy (JSDT), Tokyo, Japan

${ }^{2}$ Committee of Renal Data Registry, JSDT, Tokyo, Japan

Full list of author information is available at the end of the article
}

the Tohoku and Kanto regions, claiming a huge number of lives and inflicting tremendous damage on social infrastructures. In addition, accidents occurred at the Fukushima Daiichi Nuclear Power Station of Tokyo Electric Power Company. The Great East Japan Earthquake Disaster (GEJED) caused unprecedentedly serious and complex damage, from which the affected areas are still recovering.

Dialysis therapy, especially hemodialysis, is considered vulnerable to large-scale disasters because it uses approximately $250 \mathrm{~L}$ of water in one session of treatment, it cannot be performed without electricity, and it requires the smooth distribution of products such as 
dialyzers, blood circuits, and concentrates of dialysis fluid. There are two issues regarding dialysis therapy in times of a large-scale disaster: how to treat the acute kidney failure (AKI) due to rhabdomyolysis, which is caused by multiple injuries, and how to continue chronic maintenance dialysis. The incidents of AKI caused by multiple injuries were low in GEJED because $92.5 \%$ of the victims died from drowning in the huge tsunami [1]. The serious problem highlighted by this disaster was the difficulty in continuing maintenance dialysis due to the inundation of dialysis facilities by the tsunami, the longterm disruption of lifelines including electricity and water supplies over a wide area, and the disruption of product distribution.

In cooperation with three organizations involved in dialysis therapy, the Japanese Society for Dialysis Therapy (JSDT), the Japanese Society of Nephrology (JSN), and the Japanese Association of Dialysis Physicians (JADP), the Working Group (WG) for Survey of Dialysis Therapy during GEJED was established in order to determine what actually happened at sites of dialysis therapy during GEJED and how we can prepare for future disasters. The "Report of Survey of Dialysis Therapy during the Great East Japan Earthquake Disaster: Recommendations for Dialysis Therapy Preparation in Case of Future Disasters" was published in December 2013. This report consists of three chapters providing general statements and seven chapters providing specific discussions, summarizing the survey results and the recommendations on how to implement dialysis therapy in future disasters [2] (Table 1). This manuscript provides an overview of GEJED, the extent of damage to dialysis facilities, the disaster management measures taken, the transfer of patients, and the care provided to dialysis patients during the disaster. The recommendations for dialysis therapy preparation in case of future disasters were summarized in Appendixes 1 and 2.

Currently, while the use of dialysis therapy is rapidly expanding mainly in developing countries, large-scale disasters such as earthquakes, floods, and droughts are occurring around the world. Providing dialysis therapy in times of large-scale disasters is now a global concern. We have realized through GEJED that it is our important responsibility to share the experiences with the world and to make recommendations for the continued provision of dialysis therapy in times of disaster.

\section{Overview of damages from GEJED}

Overview of the earthquake off the Pacific Coast of Tohoku

The earthquake that caused GEJED occurred at 14:46 on 11 March 2011 and was named the Earthquake off the Pacific Coast of Tohoku. The epicenter was located approximately $130 \mathrm{~km}$ east-southeast off the Oshika Peninsula at a depth of $24 \mathrm{~km}$. The magnitude of the earthquake was M9.0 [3], which was the largest in the recorded history in Japan and the fourth largest in the

Table 1 Contents of report on survey of dialysis therapy during GEJE

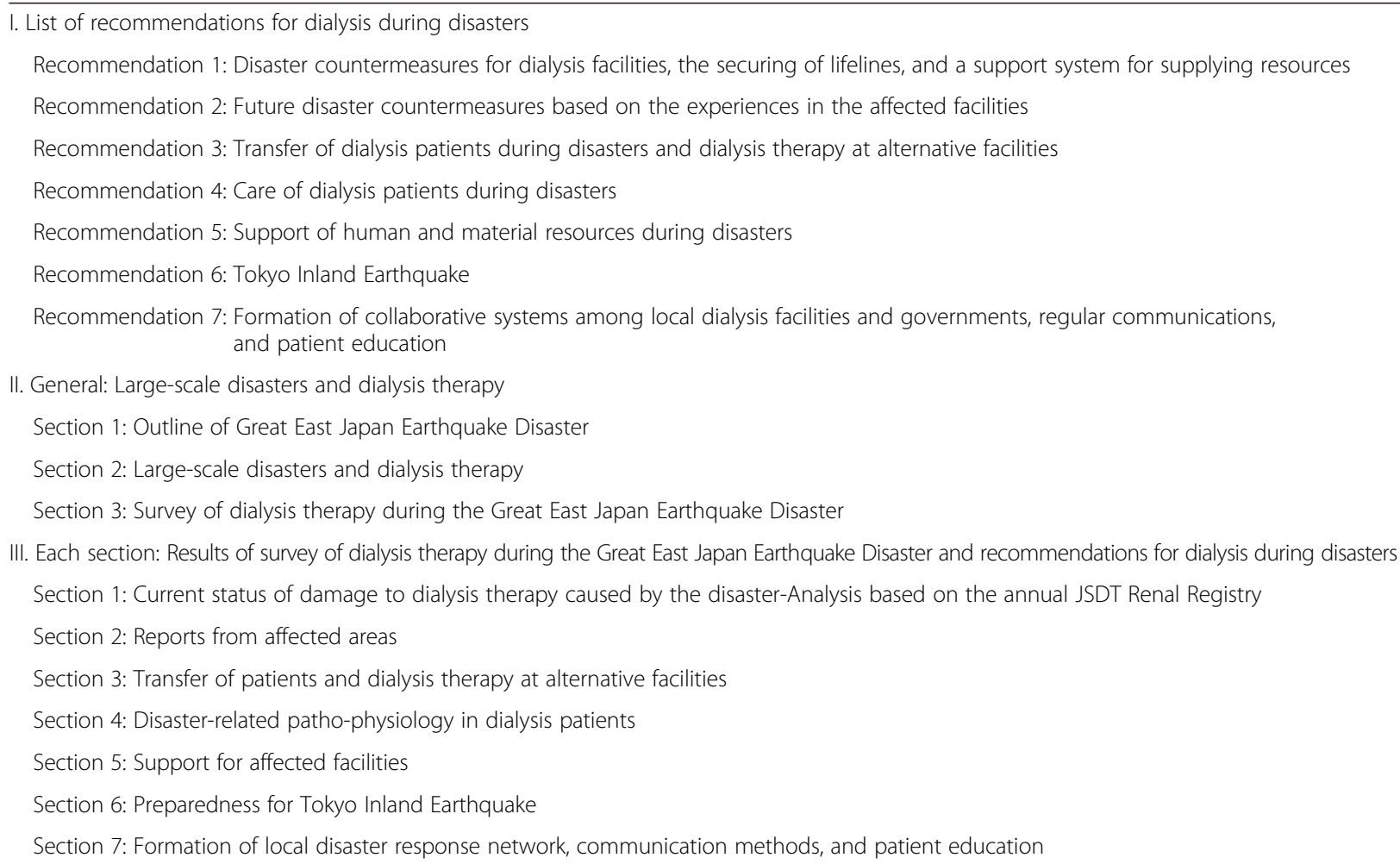


world after the Chilean earthquake in 1960 (M9.5), the Alaska earthquake in 1964 (M9.2), and the Indonesia Sumatra earthquake in 2004 (M9.1). The maximum seismic intensity was 7 on the Japanese scale, which was recorded in the northern area of Miyagi Prefecture. The seismic intensity was $6+$ in 36 cities, towns, and villages in four prefectures (Miyagi, Fukushima, Ibaraki, and Tochigi Prefectures), and in Miyagino, Sendai City [3] (Fig. 1). This was the third time that a seismic intensity of 7 was recorded in Japan following the Southern Hyogo Prefecture Earthquake that caused the Great Hanshin-Awaji Earthquake in 1995 and the Niigata Chuetsu-oki Earthquake in 2007.

The Earthquake off the Pacific Coast of Tohoku occurred around the Japan Trench, which is the boundary of the North American plate and the Pacific plate that is sliding underneath the North American plate. This earthquake was of the "consolidated type," namely, the earthquakes caused by three fault ruptures off the coast of Miyagi Prefecture, further off the coast, and in the adjacent sea of the northern area of Ibaraki Prefecture, were linked to each other. As a result, the ruptured part of the fault extended approximately $400 \mathrm{~km}$ in the north-south direction and $200 \mathrm{~km}$ in the west-east direction, generating a huge tsunami that hit a wide area from Hokkaido to Chiba Prefecture. The recorded height of the tsunami was more than $10 \mathrm{~m}$ along the Pacific coast of Aomori to Chiba Prefectures, 6-8 $\mathrm{m}$ along the Pacific coast of Hokkaido, 2-3 m along the Pacific coast of Tokai region, the Kii Peninsula, and Shikoku, and 1-2 $\mathrm{m}$ along the Pacific coast of Kyushu (Fig. 1). The inundation height, which was related to facility damage, increased southward from the central part of Aomori Prefecture, exceeding $10 \mathrm{~m}$ in the northern area of Iwate Prefecture, and reaching around $10-15 \mathrm{~m}$ along the Sanriku Coast including the Oshika Peninsula. The maximum inundation height along Sendai Bay was estimated to be $8-9 \mathrm{~m}$. The maximum run-up height was $40.1 \mathrm{~m}$ which was recorded in Ofunato City, Iwate Prefecture. The tsunami destroyed breakwaters, devastated towns, ran up rivers, and even caused damage to settlements $6 \mathrm{~km}$ inland. The area affected by the inundation due to the tsunami and ground subsidence was $561 \mathrm{~km}^{2}$ and extended from Aomori to Chiba Prefectures.

\section{Overview of damage}

(a) Damage to human life

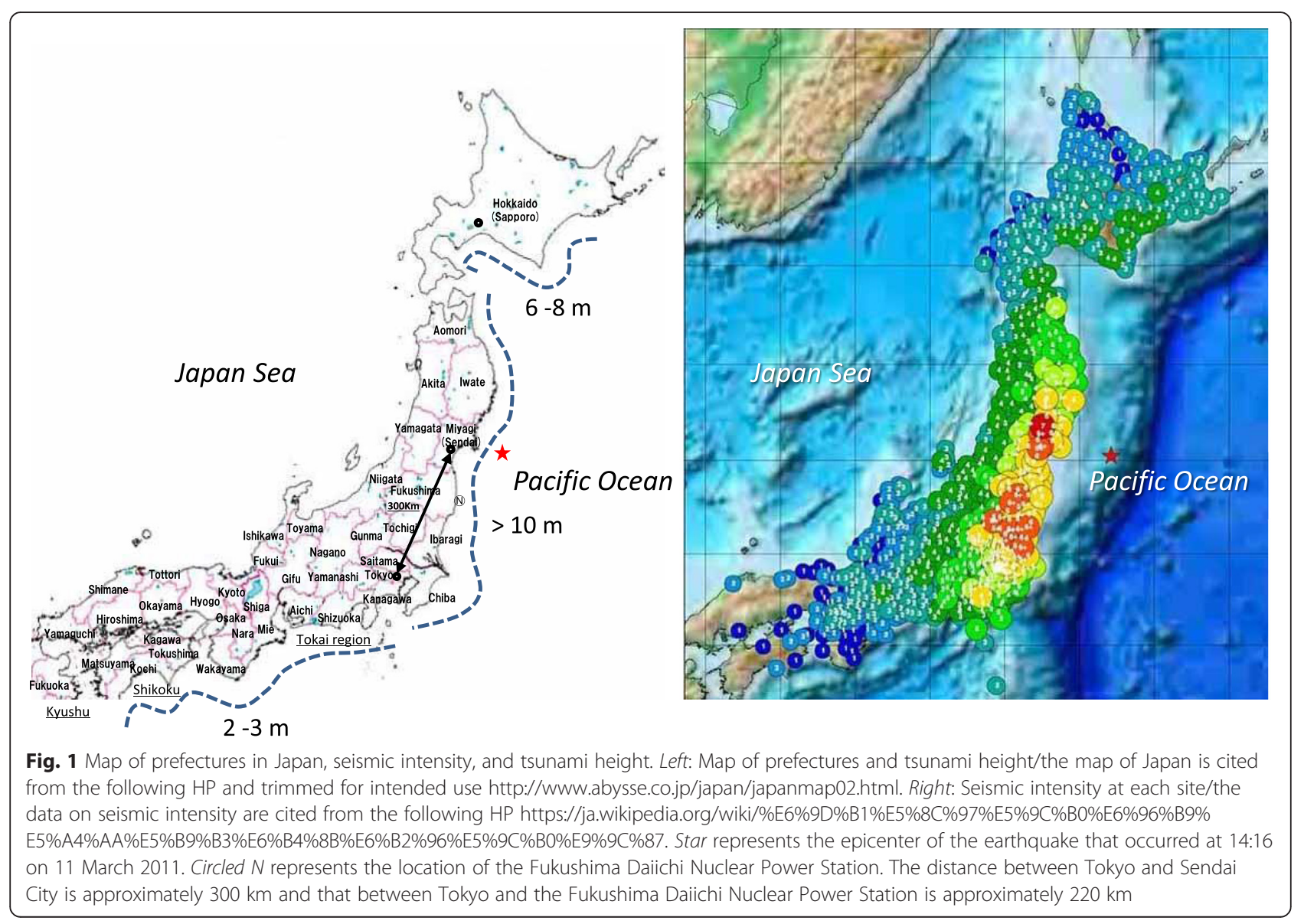


According to the official announcement of the Fire and Disaster Management Agency on 9 September 2015 regarding the Earthquake off the Pacific Coast of Tohoku, the death toll from the disaster was 19,335 as of 1 September 2015; 5127 people died in Iwate Prefecture, 10,538 in Miyagi Prefecture, 3559 in Fukushima Prefecture, 65 in Ibaraki Prefecture, and 22 in Chiba Prefecture [4] (Table 2). The death toll was high in the prefectures severely damaged by the tsunami, and the death toll in Iwate, Miyagi, and Fukushima Prefectures in the Tohoku region accounted for $99.6 \%$ of the total death toll. The highest death toll ever in Japan was 105,000 for the Taisho Great Kanto Earthquake followed by that in GEJED, which was more than threefold that for the Great Hanshin-Awaji Earthquake Disaster (GHAED) in 1995 (6434 dead and 3 missing) (Table 2). According to the National Police Agency Report, as of 11 April 2011, the causes of death of 13,135 people autopsied in Iwate, Miyagi, and Fukushima Prefectures were $92.5 \%$ drowning, $4.4 \%$ crushing and fatal injuries, $1.1 \%$ death by fire, and $2 \%$ unknown [1]. The number of missing persons was 2600 as of 1 September 2015; 1129 in Iwate Prefecture, 1242 in Miyagi Prefecture, 225 in Fukushima Prefecture, and 4 in other prefectures. The search for missing persons is continuing. On the other

Table 2 Comparison of the Great East Japan Earthquake Disaster (GEJED) and the Great Hanshin-Awaji Earthquake Disaster (GHAED)

\begin{tabular}{|c|c|c|}
\hline & GEJED & GHAED \\
\hline Dead & 19,335 & 6434 \\
\hline Missing & 2,600 & 3 \\
\hline Irjured & 6,219 & 43,792 \\
\hline Evacuees & Approx. 470,000 & Approx. 320,000 \\
\hline \multicolumn{3}{|l|}{$\begin{array}{l}\text { Damage to residential } \\
\text { buildings }\end{array}$} \\
\hline $\begin{array}{l}\text { Completely } \\
\text { destroyed }\end{array}$ & 124,690 & 104,906 \\
\hline Half destroyed & 275,118 & 144,274 \\
\hline Partially damaged & 764,843 & 390,506 \\
\hline $\begin{array}{l}\text { Damage to } \\
\text { nonresidential buildings }\end{array}$ & 91,509 & 42,496 \\
\hline Damage to roads & 4,200 sections & 7,245 sections \\
\hline Damage to bridges & 116 sections & 774 sections \\
\hline $\begin{array}{l}\text { Period of traffic } \\
\text { restrictions }\end{array}$ & 12 days & 1 year and 7 months \\
\hline Water outages & $\begin{array}{l}\text { Approx. } 0.045 \text { million } \\
\text { households }\end{array}$ & $\begin{array}{l}\text { Approx. } 1.3 \text { million } \\
\text { households }\end{array}$ \\
\hline Gas supply interruptions & $\begin{array}{l}\text { Approx. } 0.42 \text { million } \\
\text { households }\end{array}$ & $\begin{array}{l}\text { Approx. } 2.6 \text { million } \\
\text { households }\end{array}$ \\
\hline Power outages & $\begin{array}{l}\text { Approx. } 8.44 \text { million } \\
\text { households }\end{array}$ & $\begin{array}{l}\text { Approx. } 2.6 \text { million } \\
\text { households }\end{array}$ \\
\hline Telephone interruptions & $\begin{array}{l}\text { Approx. } 1.9 \text { million } \\
\text { lines (fixed line) }\end{array}$ & $\begin{array}{l}\text { More than } 0.3 \\
\text { million lines }\end{array}$ \\
\hline
\end{tabular}

hand, the number of missing persons was only 3 in GHAED, which was a near-field earthquake and not followed by tsunami. The total number of persons injured by GEJED was 6219; 4145 in Miyagi Prefecture, 712 in Ibaraki Prefecture, 256 in Chiba Prefecture, 211 in Iwate Prefecture, and 183 in Fukushima Prefecture. The number of injured persons in Miyagi Prefecture accounted for $66.7 \%$ of the total, but the people were distributed over a wide area from the Tohoku to Kanto regions. In GHAED, the number of persons injured by the collapse of buildings was 43,792, which was approximately sevenfold that in GEJED. On the other hand, most of the human damage in GEJED was caused by the tsunami.

\section{(b)Structural damage}

As previously mentioned, the number of deaths due to the collapse of buildings was lower in GEJED than in GHAED because of the differences in the characteristics of the earthquake waves. However, because GEJED affected a broad area, the number of damaged buildings was higher than that in GHAED. Nationwide, the number of completely destroyed buildings was 124,690; half destroyed buildings, 275,118; and partially damaged buildings, 764,843 (Table 2). Nevertheless, the number of persons who died from crushing and the number of injured persons were very low compared with those in GHAED probably because of the differences in the characteristics of the earthquake waves, the building density and structures, and the population density in the affected area. The number of damaged sections of roads and the number of damaged bridges were 4,200 and 116, respectively, in GEJED, both of which were lower than the corresponding numbers in GHAED (7,245 and 774, respectively). This may arise because of differences in the density of infrastructure in the affected areas (Table 2).

\section{(c) Traffic disturbance}

On 12 March 2011, some sections of the Tohoku Expressway, Joban Expressway, and Ban-etsu Expressway were designated as emergency traffic routes based on the Disaster Countermeasure Basic Act, and private passenger vehicles were restricted. These restrictions were gradually lifted as the expressways were repaired, and all the traffic restrictions on the major expressways were lifted on 24 March 2011.

\section{(d)Disruption of lifelines}

According to the government report published on 27 November 2012, the overview of the disruption of lifelines in GEJED was as follows; water supplies were 
disrupted for approximately 45,000 households; gas supply interruption, approximately 420,000 households; and power outages, approximately 8,440,000 households. Power outages affected significantly larger areas in GEJED than in GHAED (Table 2). Long-term interruption of the power supply occurred in a broad area particularly because of the accidents at the Fukushima Daiichi Nuclear Power Station of Tokyo Electric Power Company and the damage to thermal power stations. As a result, rolling blackouts were implemented across the country and the continuation of daily dialysis therapy was severely interrupted even in areas not directly hit by the earthquake.

GEJED caused massive damage to information and telecommunication infrastructures, including the breakage of transmission lines due to the earthquake and subsequent tsunami, the dysfunction of telecommunication buildings due to large-scale power outages, and the damage to cellular base stations. Approximately 1.9 million lines of four telecommunication providers and a maximum of 29,000 cellular and PHS base stations of five mobile telecommunication providers were out of service at that time. Telecommunications companies imposed communication restrictions in the early stages of the disaster, which largely interrupted information gathering and transmission as well as the confirmation of the safety of victims in the affected areas. Some social networking services on the Internet were effective under these circumstances and attracted attention as new ways to collect information and communicate in the affected areas. In addition, free services on public pay phones, specially installed public pay phones, emergency message services, and other measures of telecommunication were made available at that time. The communication, which failed because of the damage to information and telecommunication infrastructure, was recovered by the end of April 2011 in most areas.

\section{Accidents at the Fukushima Daiichi Nuclear Power Station of Tokyo Electric Power Company}

The damage caused by GEJED became severe and complicated because of the accidents at Fukushima Daiichi Nuclear Power Station of Tokyo Electric Power Company that followed the Earthquake off the Pacific Coast of Tohoku. The nuclear reactors operating at Daiichi and Daini Nuclear Power Stations shut down automatically immediately after the earthquake. After that, however, all $\mathrm{AC}$ power in these nuclear power stations was lost when the facilities were hit by the tsunami, making it impossible to cool their reactor cores. A nuclear emergency was declared at the Fukushima Daiichi Nuclear Power Station at 19:03 on March 11 and at the Fukushima Daini Nuclear Power Station at 7:45 on March 12. Efforts were made to prevent hydrogen explosions by venting (the release of steam out of a nuclear reactor containment to lower the pressure inside) and by pouring water into the nuclear reactor. However, hydrogen explosions occurred in Unit 1 at 15:36 on March 12, in Unit 3 on March 14, and in Unit 2 on March 15, resulting in the release of large amounts of radioactive materials. These accidents were reported to the International Atomic Energy Agency (IAEA) as level 7, the worst on the nuclear accident scale, on April 12.

At 21:23 on March 11, the Prime Minister ordered all residents within a $3-\mathrm{km}$ radius of the Fukushima Daiichi Nuclear Power Station to evacuate and also all residents within a $3-10-\mathrm{km}$ radius to stay inside their houses. Afterward, the evacuation area was expanded to a $20-\mathrm{km}$ radius and the "stay in-house area" to a $20-30-\mathrm{km}$ radius by March 15 . Because of these evacuation orders for a broad area and the rumors concerning radioactive contamination, it became impossible to continue chronic maintenance dialysis therapy in that area and a number of dialysis patients needed to be transferred to other areas. On March 16, the US Government ordered all Americans in Japan within an 80-km radius of Fukushima to evacuate according to the advisory from IAEA. It was later pointed out that local residents were exposed to radioactive contamination because the results of the System for Prediction of Environmental Emergency Dose Information (SPEEDI) were not disclosed immediately after the accidents. Whether the evacuation area set by the Japanese government was appropriate or not has been examined [5]. If the evacuation area had been set at an 80$\mathrm{km}$ radius according to the IAEA, it would have included not only the cities of Koriyama and Fukushima but also Hitachi City in Ibaraki Prefecture all of which have many dialysis patients. It is beyond our imagination how many dialysis patients would have needed to be transferred and what kind of measures would have been required.

\section{Disaster planning before GEJED \\ Disaster information network of the JADP}

According to the cabinet office, Japan has experienced $20.6 \%$ of earthquakes of M6 or higher, has $7.0 \%$ of the number of active volcanos, and has sustained $18.3 \%$ of the damage from disasters all over the world, although its total land area is only $0.25 \%$ of the total world land area. Japan is one of the most disaster-prone countries in the world [6]. Through its experience in a number of large-scale disasters, chronic dialysis therapy has become recognized as vulnerable to disasters, and various countermeasures with regard to this therapy have been established. As a result, the disaster information network on dialysis therapy correctly grasped the extent of damage and immediately established a dialysis support system during GEJED. This network was developed mainly by JADP after GHAED in 1995. Not only dialysis facilities throughout the country but also the disaster management 
department of the national and local governments participate this network, which is very effective for sharing realtime information in times of disaster.

JADP was established from the association of municipal societies of dialysis physicians in 1985. Since then, it has focused on preparation for disasters as one of its primary activities. In November 1987, the association launched an emergency dialysis therapy system for disasters, which is a system of registering data on dialysis facilities and patients with the aim of providing support in times of large-scale disaster and promoting research studies in ordinary times. In 1995, 1243 facilities (43.4 \% of the facilities in the country) and 48,389 patients $(31.3 \%$ of the patients in the country) were registered in the system. However, this system did not work as expected in GHAED in 1995 because of the unexpectedly large extent of damage, and a large number of patients experienced difficulty in receiving dialysis therapy. From the experience in GHAED, JADP specified "the secure provision of dialysis therapy to patients undergoing maintenance dialysis and patients with AKI caused by crush syndrome in times of disaster as the primary purpose" of the preparation for disasters. The core activity of JADP focused on the establishment of a disaster management plan by the participating facilities and, for that purpose, the establishment of branch offices of JADP in each prefecture. Since 1999, the Internetbased information system for disasters, which had already been operating in Chiba Prefecture, has developed into a nationwide system. An information transmission drill has been performed once a year since 2000 up to the present.

The disaster information network of JADP consists of two information-sharing tools utilizing the Internet: a web-based disaster information network created for rapidly sharing precise information among affected areas, support areas, and governments in times of disaster (http://www.saigai-touseki.net/) and a crisis-management mailing list that was created as a nationwide information-sharing tool in 2003. This disaster information network functioned well during GEJED, enabling the establishment of a dialysis support system around an affected area or in a broader area as described later in their document. As a result, dialysis support was provided across the country to more than 10,000 patients during GEJED.

\section{Approach of facilities to providing dialysis therapy during disasters}

Since GHAED in 1995, increasing attention has been paid to how to provide dialysis therapy in the event of earthquakes and how to prepare for earthquakes in dialysis rooms. Akatsuka [7], in collaboration with JADP, summarized the damage to dialysis rooms caused by the Niigata Chuetsu-oki Earthquake by referring to his experiences in the area in Hokkaido frequently hit by earthquakes, and he has emphasized the significance of preparing beforehand for earthquakes in dialysis rooms. On the basis of past experiences, it was reported that the direct damage to dialysis rooms was prevented in earthquakes of intensity 5 and that maintenance dialysis was performed even in earthquakes of intensity 6+ [7]. GEJED occurred amid the growing recognition of the significance of preparation for earthquakes in dialysis rooms. As previously mentioned, this was the third earthquake reaching the maximum intensity 7 following GHAED in 1995 and Niigata Chuetsu-oki Earthquake in 2004. The Southern Hyogo Prefecture Earthquake occurred in the early morning on a Tuesday when dialysis therapy was not performed in dialysis facilities. In the Niigata Chuetsu-oki Earthquake, there were no dialysis facilities in the area where the maximum intensity 7 was recorded. GEJED, however, occurred during the midday hours of Friday when dialysis therapy was being performed in dialysis facilities. There were dialysis facilities in the area where intensity 7 was recorded. This was a historical earthquake for dialysis therapy because it was the first time that an earthquake of intensity 7 occurred during the hours when the therapy was being performed. It was a good opportunity to see if the disaster management measures that had been implemented at dialysis facilities were effective. The various experiences obtained from this disaster will provide us with important knowledge about the preparation for large earthquakes that may occur in the future.

\section{Results of survey of dialysis therapy during GEJED Survey of dialysis therapy during GEJED}

The WG was proposed by Tadao Akizawa, the President of JSDT, at the time of the disaster in 2011. The WG consisted of the representatives of four organizations, namely, JSDT, JADP, JSN, and the Japan Association for Clinical Engineers (JACE), the representatives of the affected prefectures and the prefectures providing support, and the members of the Committee of the renal data registry of JSDT. A nationwide survey by the WG was conducted as the 2011 year-end survey by the Committee of the renal data registry of JSDT (JSDT registry) on 4255 dialysis facilities in Japan, and 4213 facilities responded. The 2011 year-end survey consisted of 21 questions for the affected areas as well as support areas, including questions about facility damage, requests for dialysis support, and disaster management measures taken at the facilities (Table 3). The response rates were about $85-95 \%$. Because more detailed information was required to summarize the recommendations for disaster management measures, an additional survey was conducted in September 2013 on 315 facilities that had answered that dialysis services were interrupted in their facilities for some reason, and 298 facilities responded. 
Table 3 Items included in survey of dialysis therapy during GEJED

\begin{tabular}{|c|}
\hline Facility damage \\
\hline 1. Seismic intensity at the facility site \\
\hline 2. Structure of buildings where dialysis equipment is located \\
\hline 3. Completion date of buildings where dialysis equipment is located \\
\hline 4. Seismic resistance of buildings where dialysis equipment is located \\
\hline Interruption of dialysis services \\
\hline 5. Experience of the interruption of dialysis services due to the disaster \\
\hline 6. Length of time taken to resume dialysis services \\
\hline 7. Reasons for the interruption of dialysis services \\
\hline Patient transfer and schedule adjustment \\
\hline 8. Requests for dialysis support to other hospitals \\
\hline 9. Acceptance of dialysis patients from other hospitals \\
\hline 10. Number of dialysis patients accepted \\
\hline 11. Schedule adjustment due to the acceptance of patients \\
\hline 12. Schedule adjustment due to the disaster \\
\hline $\begin{array}{l}\text { Disaster countermeasures at the facility (at the time of disaster/at the } \\
\text { end of 2011) }\end{array}$ \\
\hline $\begin{array}{l}\text { 13. Presence of private power generation systems that can be used } \\
\text { for dialysis theraphy and their installation sites }\end{array}$ \\
\hline $\begin{array}{l}\text { 14. Presence of water tanks (well water) for emergency use and } \\
\text { their sizes }\end{array}$ \\
\hline $\begin{array}{l}\text { 15. Earthquake-proof measures for RO systems and dialysis fluid } \\
\text { delivery systems }\end{array}$ \\
\hline 16. Piping materials used for dialysis fluid delivery systems \\
\hline 17. Earthquake-proof measures for bedside consoles \\
\hline 18. Locking of bed casters \\
\hline $\begin{array}{l}\text { 19. Means of information gathering and communication in times } \\
\text { of disaster }\end{array}$ \\
\hline 20. Preparation of emergency release \\
\hline $\begin{array}{l}\text { 21. Provision of information to patients receiving dialysis services } \\
\text { under normal conditions }\end{array}$ \\
\hline
\end{tabular}

\section{Damage to dialysis facilities and disaster management measures taken at facilities}

In GEJED, three facilities in Miyagi Prefecture experienced an earthquake of intensity 7 . It was the first time in the history of dialysis therapy that dialysis facilities were hit by an earthquake of intensity 7 while they were providing dialysis services. However, 221 dialysis facilities in the Tohoku and Kanto regions experienced an earthquake of intensity 6- or more, which accounted for $5.7 \%$ of the responding facilities. Most of the facilities located in Hokkaido and the Chubu-Tokai region and in the west of the Kinki region experienced an earthquake of intensity 4 or lower. The dialysis facilities in the Tohoku region were most severely damaged by GEJED and those in the Kanto region, which has a high population density, were also severely affected (Figs. 2 and 3). Dialysis services were interrupted for various reasons during the disaster in 315 facilities located in 16 prefectures, mostly in Tohoku and Kanto regions. The higher the intensity of the earthquake, the higher the percentage of facilities that experienced interruption: $100 \%$ of the facilities hit by an earthquake of intensity 7 experienced interruption for various reasons, $69.8 \%$ with intensity $6+$, and $51.2 \%$ with intensity $6-$ (Fig. 4). The facilities were allowed to give multiple reasons for the interruption. The most common reason was power outage, which was encountered by $72.0 \%$ of the facilities. The reasons for the interruption in all three facilities in Miyagi Prefecture, which were hit by an earthquake of intensity 7 , were power and water outages, not facility nor equipment damage from the earthquake. However, a few facilities that were hit by an earthquake of intensity 3,4 , or 5 experienced the interruption of dialysis services due to facility and equipment damage (Fig. 4).

Dialysis facilities have been encouraged to take the following four measures in preparation for earthquakes [7].

1) Un-lock the casters of floor-type dialysis monitors.

2) Lock the casters of dialysis beds.

3) Fasten dialysis fluid delivery systems and reverse osmosis (RO) systems to the floor with anchor bolts or place those devices on a base isolation stand.

4) Use flexible tubes for the connection of dialysis fluid delivery systems and RO systems to the wall of a machine room.

According to the results of the 2011 year-end JSDT registry, the measures regarding dialysis monitors and patient beds were implemented in $90 \%$ or more of the facilities. However, the fastening of large machinery, such as dialysis fluid delivery systems and RO systems and the use of flexible tubes, was implemented in less than $50 \%$ of the facilities (Table 4). While the incidence of dialysis service interruption due to facility damage was low in Miyagi Prefecture, which experienced a highintensity earthquake, some facilities in the regions where the intensity of earthquake was 5 or lower experienced interruption due to facility damage. Therefore, the relationship between earthquake-proof measures and equipment damage was examined by conducting an additional survey. The results of the additional survey showed that the incidence of equipment damage in Miyagi Prefecture, which experienced a very high-intensity earthquake, was almost the same as that in Ibaraki Prefecture, which experienced a seismic intensity one or two levels lower. Moreover, the percentage of facilities that implemented the fastening of large machinery, such as dialysis fluid delivery systems and RO systems and the use of flexible tubes, was significantly higher in Miyagi Prefecture. These results showed that it is important to fasten RO systems and dialysis fluid delivery systems to the floor and to use flexible tubes for piping to avoid the interruption of dialysis 

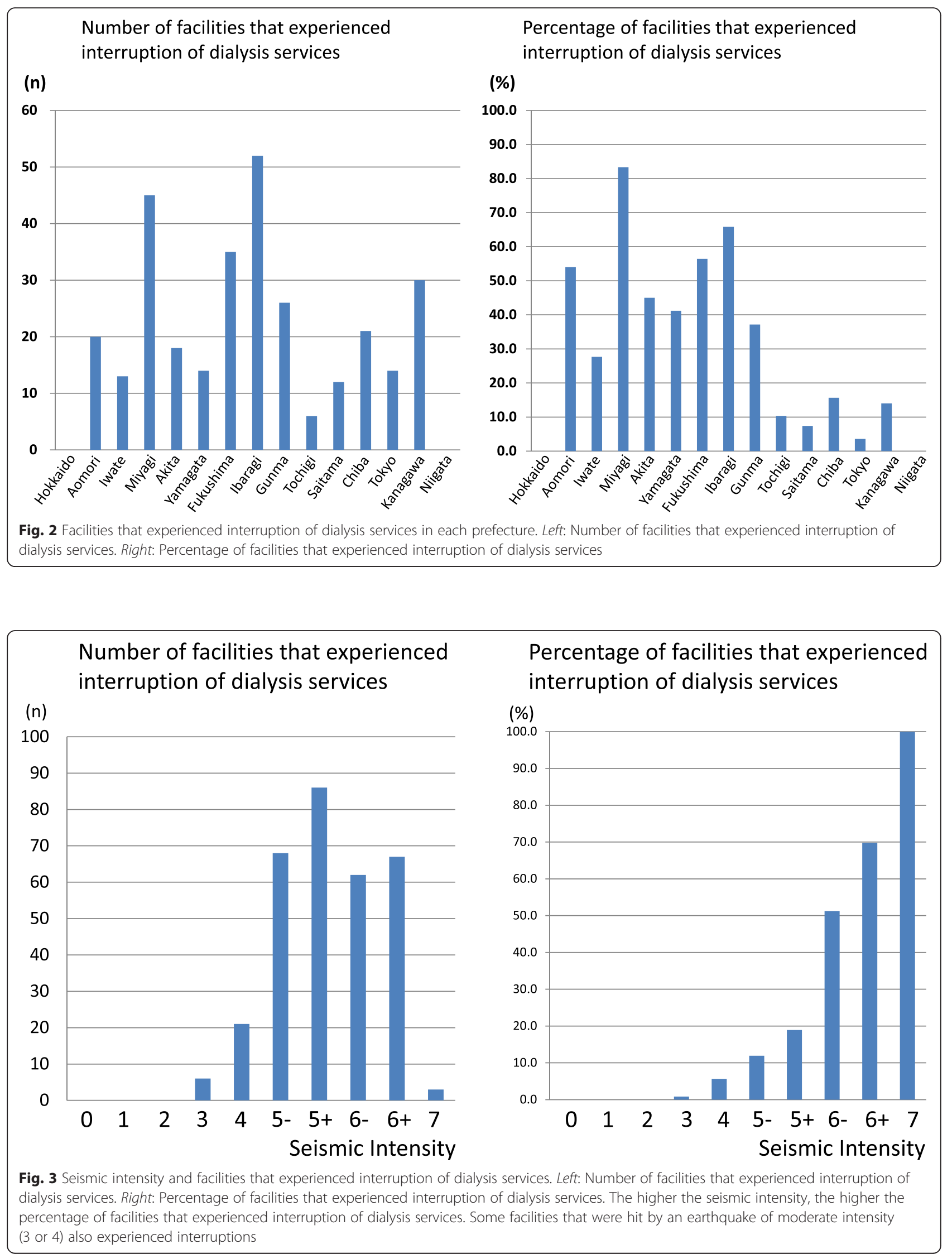


\section{Number of facilities by different reasons}

(n)

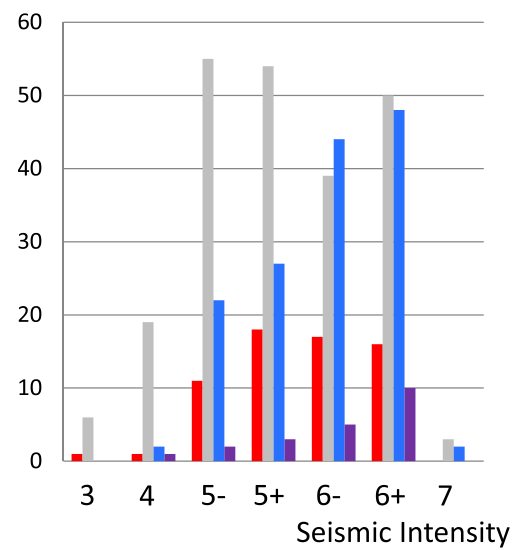

Percentage of facilities by

different reasons

(\%)

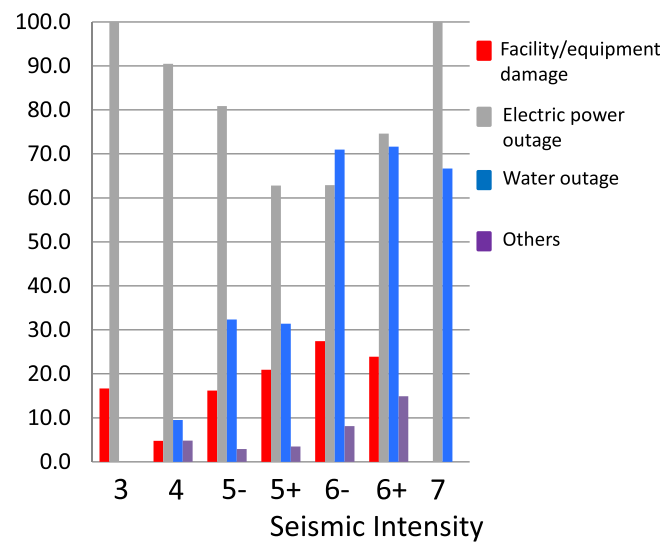

Fig. 4 Reasons for interruption of dialysis services in terms of seismic intensity. Left: Number of facilities by different reasons. Right: Percentage of facilities by different reasons. The most common reason for the interruption was power outage. Some facilities that were hit by an earthquake of moderate intensity (3 or 4) also experienced the interruption due to facility damage. Facility and equipment damage due to earthquake/power outages (except for rolling blackouts)/water outages

services due to equipment damage (Table 5). The longperiod oscillation may account for the facility damage particularly in the facilities located on the middle floors of a building in remote areas in the Kanto region, where the intensity of the earthquake was relatively low.

\section{Impact of private electric generators and water tanks}

Private electric generators, which are generally thought to be useful for providing dialysis services in the event of power outages, were installed in $55.4 \%$ of the 3559 facilities that responded to the relevant question. There was a substantial difference among prefectures in the installation of private electric generators. The percentage of facilities having private electric generators was low in the prefectures with large, densely populated cities; the lowest was in Tokyo (37.3 \%) followed by Chiba (38.2 \%) and Osaka (39.4\%). The status of the installation of water tanks was almost the same as that of private electric generators. However, among the 315 facilities that experienced the interruption of dialysis services, $67.7 \%$ of the 124 facilities that had private electric generators indicated "power outage" as the reason for the interruption. The additional survey revealed these

Table 4 Percentage of facilities that implemented four measures at the time of disaster

\begin{tabular}{ll}
\hline (1) Not locking dialysis monitors & $92.3 \%$ \\
(2) Locking dialysis beds & $93.2 \%$ \\
(3) Fastening dialysis fluid delivery systems and RO system & $48.4 \%$ \\
(4) Using flexible tubes & $47.1 \%$ \\
\hline
\end{tabular}

2011 year-end survey by the JSDT registry reasons why this was the case: they could not generate a sufficient amount of power needed for maintenance dialysis; they could not obtain oil for the generators; or the electric generators did not work because of a lack of regular maintenance. Similarly, among the 315 facilities that experienced interruptions in dialysis service, $45.5 \%$ of the 110 facilities that had water tanks indicated "water outage" as the reason for the interruption. These outages occurred because of power outages, water supply shortages, and damage to water storage equipment. As already mentioned, even when dialysis facilities install private electric generators and water tanks, there is a possibility that such equipment will not work depending on the scale and characteristics of disasters. Such equipment cannot provide absolute security. It is important to develop a mutual assistance system to meet the needs in each area.

\section{Patient transfer for maintenance dialysis in alternative place} Of the 315 facilities that experienced the interruption of dialysis services, almost half (161 facilities) requested other facilities to provide dialysis to their patients. We asked the dialysis facilities nationwide whether they accepted dialysis patients transferred to them from the affected areas. Of the 3928 responding facilities, 992 facilities answered that they accepted such patients. The number of patients accepted was 10,906 in total, and the numbers of hospitalized patients and outpatients were 1078 and 9828, respectively (Table 6). Most of the patients were transferred to the Kanto region or surrounding prefectures that were not severely damaged, while some patients were transferred within the affected areas, namely, Miyagi, Ibaraki, Fukushima, and Iwate 
Table 5 Percentage of facilities that implemented four measures and percentage of facilities where equipment was damaged in three prefectures

\begin{tabular}{llllll}
\hline & $\begin{array}{l}\text { Fastening dialysis fluid delivery systems } \\
\text { and RO systems to floor (\%) }\end{array}$ & $\begin{array}{l}\text { Using flexible tubes for } \\
\text { connection (\%) }\end{array}$ & Dialysis monitors (\%) & Dialysis beds (\%) & Equipment damage (\%) \\
\hline Miyagi & 92.5 & 92.5 & 87.8 & 85.2 & 14.3 \\
Fukushima & 73.2 & 58.9 & 90.9 & 86.2 & 26.4 \\
Ibaraki & 43.8 & 50.0 & 85.8 & 93.3 & 11.4 \\
\hline
\end{tabular}

Additional survey of 298 facilities

Prefectures. One of the remarkable aspects of this disaster was that a large-scale patient transfer was required because the continuation of dialysis therapy became impossible in wide areas because of the damage to infrastructure caused by the huge tsunami and the damage to local medical resources caused by the accidents at the power stations of Tokyo Electric Power Company. Eighty patients were transferred from Kesennuma in Miyagi Prefecture to Hokkaido, and 382 patients were transferred from Iwaki City in Fukushima Prefecture to Tokyo, 154 to Niigata Prefecture, and 45 to Chiba Prefecture (Fig. 5). Japan SelfDefense Force planes were used to transfer the patients from Miyagi Prefecture to Hokkaido, and large buses were used to transfer the patients from Iwaki City. In the past experiences, electricity was restored within $48 \mathrm{~h}$ and water supplies were restored within 4 days even after a large earthquake. However, in GEJED the disruption of infrastructure lasted a long time in the areas damaged by the tsunami, particularly in Miyagi Prefecture, and it took a long time to restore the infrastructure needed to provide maintenance dialysis. Therefore, the WG proposed that, when the interruption of dialysis services lasts for more than 4 days and is expected to be further prolonged, the transfer of patients to other facilities outside affected areas should be considered.

Table 6 Number of facilities that accepted more than 100 dialysis patients and number of patients accepted in each prefecture

\begin{tabular}{lll}
\hline Prefectures & Facilities & Patients \\
\hline Miyagi & 41 & 3347 \\
Ibaraki & 60 & 1927 \\
Fukushima & 51 & 1600 \\
Tokyo & 211 & 823 \\
Tochigi & 44 & 749 \\
Chiba & 80 & 420 \\
Iwate & 36 & 392 \\
Kanagawa & 104 & 364 \\
Saitama & 82 & 272 \\
Yamagata & 26 & 246 \\
Niigata & 27 & 206 \\
Akita & 11 & 130 \\
Total & 992 & 10,906 \\
\hline
\end{tabular}

Along with the acceptance of patients, 257 facilities ( $25.9 \%$ of the facilities that accepted the patients) changed their dialysis schedule, most of them for less than a month. However, the dialysis schedule was adjusted because of rolling blackouts in 736 facilities, which was far more than the number of facilities that accepted the patients. The schedule needed to be adjusted because of rolling blackouts in the Tohoku, Hokkaido, Kanto, Koshinetsu, and Chubu regions but not in the Kinki, Shikoku, and Kyushu regions. In times of large-scale disaster, rolling blackouts will become a problem not only in affected areas but also across the country.

\section{PD therapy in times of disaster}

While hemodialysis is an in-house treatment largely relying on infrastructure for electricity, water supply, and smooth distribution of products among other needs, peritoneal

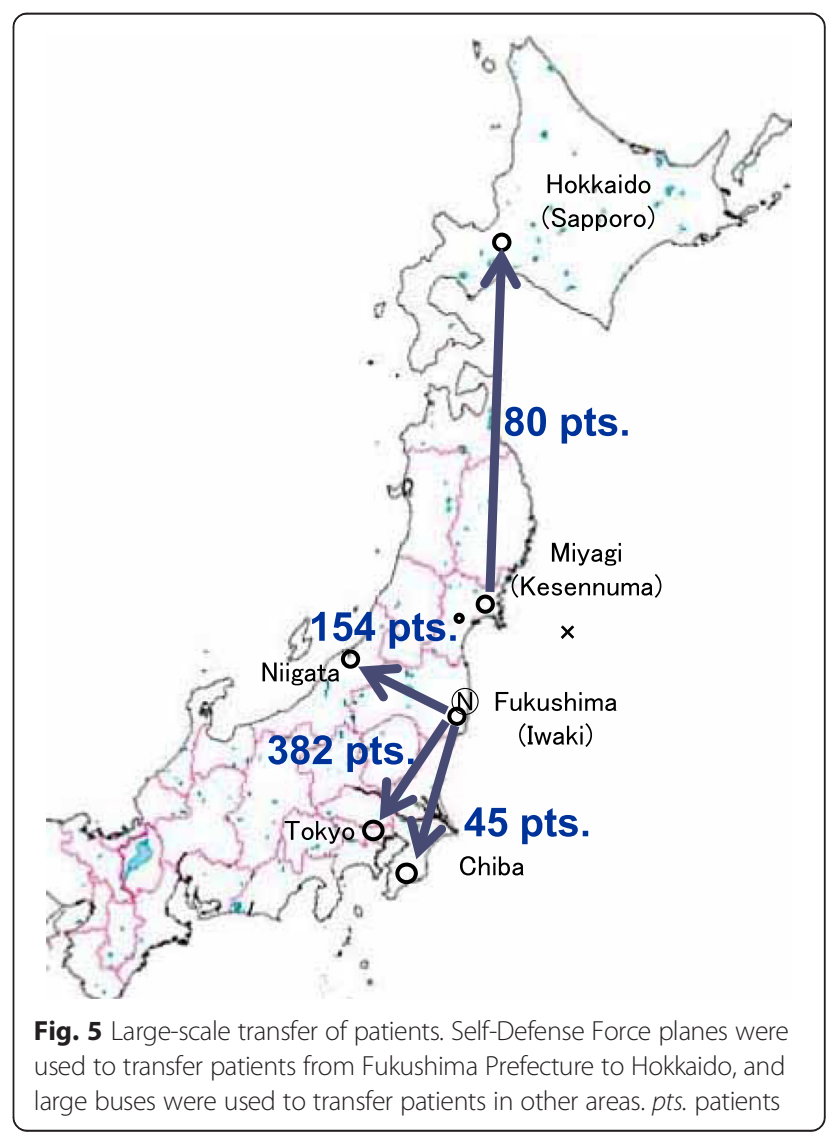


dialysis (PD) is a home-based treatment relying less on infrastructure. As described previously, in GEJED, the continuation of hemodialysis became impossible because of the damage to the infrastructure in wide areas caused by the earthquake and subsequent tsunami. More than 10,000 patients across the country needed dialysis support, and it was necessary to transfer a large number of patients from Miyagi and Fukushima Prefectures. The status of PD patients in GEJED has not been investigated in detail probably because the incidence of severe problems encountered in continuing PD therapy was significantly lower than that for hemodialysis. The following describes the status of PD patients in Iwate, Miyagi, and Fukushima Prefectures that were severely damaged by the disaster.

There were 144 PD patients in Iwate Prefecture when the disaster occurred. Of them, one patient who lived in the coastal area died in the tsunami, 12 patients were hospitalized because of power outages, and 5 patients needed hospital treatment for medical conditions such as peritonitis. There were 36 patients living in the coastal area severely damaged by the tsunami. Of them, 13 patients needed to move to other areas to receive dialysis because their houses were washed away or inundated or because of the long-term power outage. Twenty-two patients could stay in their homes and continue dialysis. Because the inland area of Iwate Prefecture was less devastated and the prefectural hospitals were well prepared for disasters, the facilities in the inland area could provide early support to the facilities in the coastal area. The problem that arose in all areas was how to secure a stable power supply for connection devices and automated PD (APD) machines during the power outage. This problem was overcome by using the manual exchange technique called continuous ambulatory PD (CAPD) or by recharging the devices at fire departments. After the power supply was restored, PD was continued stably.

There were 63 PD patients in Miyagi Prefecture, and one of them who lived in the coastal area died in the tsunami. There were 20 PD outpatients in the Japan Community Health Care Organization (JCOH) of Sendai Hospital, located at the central inland area of the prefecture, and they had fewer problems than the hemodialysis patients who faced many serious problems. Of the 20 patients, 12 were CAPD patients. They had a sufficient stock of dialysis fluids in their homes and therefore continued the home-based treatment. Eight were APD patients, and five of them could not continue APD because of power outages. They continued dialysis by changing from APD to CAPD and soon went back to APD after the power supply was restored. Two patients were hospitalized, one because the patient's house was damaged, and the other because the patient developed peritonitis after changing the dialysis mode. The hospital provided dialysis support to hemodialysis patients from 36 facilities beginning the day after the occurrence of the disaster, but there were no PD patients from other facilities who needed dialysis support. There were 17 PD patients in Senseki Hospital located at the coastal area of the prefecture, and one of them died in the tsunami. Because the area was severely damaged by the tsunami, these patients faced many problems such as the washing away of houses and dialysis equipment, long-term power outages, and difficulties in securing a place for the exchange of dialysis fluids. The hospital also had a small stock of dialysis fluids, so it offered a limited range of dialysis services while waiting for the emergency delivery of dialysis fluids.

There were 152 PD patients in Fukushima Prefecture. The hospital staff and the PD companies tried to confirm the safety of patients and could contact all the patients except for one missing patient within a week of the disaster. Some patients could not receive PD therapy at their hospitals, but they received PD therapy at the back-up hospitals. The provision of dialysis support was not a burden to those hospitals because the frequency of hospital visits was usually once every 2 to 4 weeks for PD patients.

The reports from the affected areas showed that, as we expected, the problems affecting PD patients were much fewer than those affecting hemodialysis patients. The reasons for this may be that PD relies less on social infrastructure for electricity and water supply and that there is no problem about the transportation to dialysis facilities because PD is a home-based treatment with a certain amount of dialysis fluids stored at patients' homes. During GEJED, the transportation available to hemodialysis patients was very limited because of the damage to roads across wide areas caused by the tsunami or the lack of gasoline due to the interruption of product distribution. The residential area of PD patients is larger than that of hemodialysis patients, and medical institutes may have difficulties in confirming the safety of their patients. However, the PD companies regularly contact patients requiring their delivery of PD fluid and those companies can help confirm the safety of the patients. Although electricity is needed for bag-exchange devices and APD, PD can be continued during the acute phase after a disaster by changing from APD to CAPD, as mentioned in the report from the affected areas. We have concluded that PD was far more resilient to disasters than hemodialysis, as shown by the experiences in GEJED.

\section{Clinical conditions of dialysis patients in times of disaster}

As described previously, there are two problems in dialysis therapy during large-scale disasters: the provision of dialysis as an emergency treatment and the maintenance of 
chronic dialysis. These two aspects are closely related because, when a large number of patients develop AKI due to crush syndrome and require dialysis therapy, it affects the continuation of chronic maintenance dialysis. When the patients undergoing maintenance dialysis develop crush syndrome, their clinical condition is considered urgent or life-threatening because of the effects of hyperkalemia and acidosis due to muscle degeneration. The immediate transfer to emergency care hospitals is crucial for their survival.

The death toll for GEJED was 19,335 (official announcement of the Fire and Disaster Management Agency on 9 September 2015 [4]), which was nearly threefold that for GHAED. In GEJED, the causes of death were $92.5 \%$ of the victims drowning in tsunami, $4.4 \%$ crushing and fatal injuries, $1.1 \%$ fire, and $2 \%$ unknown [1]. On the other hand, in GHAED, $85.7 \%$ of the victims died as a direct result of the earthquake. Among them, $72.6 \%$ died from suffocation and crushing, $7.8 \%$ died from traumatic shock, and $7.4 \%$ died from fire. In GEJED, most of the victims died from drowning and few patients developed acute renal disorder. Hence, medical institutes focused on continuing maintenance dialysis.

In times of large-scale disaster, various cardiovascular events are induced by increased sympathetic nervous system tone due to physical and psychological stress and thrombotic tendency due to decreased daily activity. Dialysis patients often have to eat the same meals as other evacuees at evacuation centers. Therefore, they face the risk of various health problems, including congestive heart failure due to excess salt intake and hyperkalemia, or they may develop dehydration due to the excessive care about hyperkalemia and excess salt intake [8].

There have been reports from the affected areas about the hemodynamic changes of dialysis patients in GEJED. Some reported that there was no change in blood pressure, while many reported that a temporary increase in blood pressure was observed after the disaster. The increase in blood pressure was not caused by an increase in extracellular body fluid but may be caused by stress. The JCHO Sendai hospital in Miyagi Prefecture reported that 67 patients were hospitalized because of congestive heart failure during the 3 months following the disaster, which was more than twice that during the same period of the preceding year (29 patients).

According to the comparison of the cause of death in dialysis patients in 2010 [9] and 2011 [10], there was a larger increase in the number of deaths from the disaster and from heart failure in Iwate, Miyagi, and Fukushima Prefectures, which were hit by the disaster, compared with the national average and the average of the four prefectures in Shikoku where the impact of the disaster was small (Table 7). On the other hand, according to the general population census statistics of the Ministry of Health, Labor, and Welfare [10], the number of deaths from accidents, heart disease, and pneumonia increased in the general population in the three devastated prefectures (Table 8). These data suggest that dialysis patients are prone to develop heart failure.

As described, it is acknowledged that both dialysis therapy and chronic dialysis patients are vulnerable in disasters. Sakai [11] reported that even dialysis patients who appeared in good condition in the aftermath of $t$ GHAED died suddenly, due to brain hemorrhage, gastrointestinal bleeding, or unknown causes, 6 months or later after the earthquake, indicating how much stress the patients experience in the time of large-scale disasters. Kario also reported that patients were prone to develop cardiovascular events in times of disaster, but that patients who were taking $\alpha$ - or $\beta$-blockers and diabetic patients with autonomic neuropathy showed less increase in blood pressure [12]. Elevated blood pressure in facilities and home was also reported in GEJED [13, 14]. Tanaka et al. suggested the advantage of RAS inhibitors for home blood pressure stability under a disaster [14].

On the basis of these survey results and past reports, the WG proposed that chronic dialysis patients should have adequate sleep and keep their body and mind at rest, should measure their blood pressure and pulse and receive appropriate antihypertensive treatment including sympathetic blockers, and should avoid over-hydration and dehydration in times of disaster.

\section{Conclusions}

The survey of dialysis therapy during GEJED showed that, as previously suggested, both dialysis therapy and patients undergoing maintenance dialysis are vulnerable

Table 7 Number of deaths from specific causes per 1000 dialysis patients in 2011 compared with previous year

\begin{tabular}{lllllll}
\hline & Total deaths (\%) & Heart failure (\%) & Cerebral vascular (\%) & Infection (\%) & Malignancy (\%) & Disaster (\%) \\
\hline Iwate & 102.7 & 113.8 & 99.3 & 72.5 & 78.7 & 827.3 \\
Miyagi & 114.7 & 106.3 & 101.0 & 129.6 & 59.7 & 1645.6 \\
Fukushima & 117.0 & 126.0 & 103.8 & 104.2 & 80.3 & 169.2 \\
Three prefectures in Tohoku & 112.3 & 115.2 & 101.6 & 102.4 & 71.6 & 887.9 \\
Four prefectures in Shikoku & 101.8 & 89.9 & 91.3 & 114.7 & 124.0 & 227.8 \\
Entire country & 103.5 & 102.0 & 98.1 & 103.7 & 96.1 & 166.1 \\
\hline
\end{tabular}


Table 8 Number of deaths from specific causes per 100,000 general population in 2011 compared with previous year

\begin{tabular}{llllllc}
\hline & Total deaths (\%) & Heart disease (\%) & Cerebral vascular (\%) & Pneumonia (\%) & Malignancy (\%) & Accident (\%) \\
\hline Iwate & 143.0 & 108.2 & 112.4 & 108.1 & 100.1 & 1107.3 \\
Miyagi & 156.4 & 113.2 & 105.5 & 120.4 & 99.0 & 1517.2 \\
Fukushima & 116.9 & 114.4 & 102.5 & 115.8 & 102.3 & 315.6 \\
Three prefectures in Tohoku & 137.8 & 111.8 & 107.2 & 114.1 & 100.5 & 938.8 \\
Four prefectures in Shikoku & 102.8 & 101.6 & 102.3 & 105.1 & 99.7 & 100.1 \\
Entire country & 104.9 & 103.1 & 100.5 & 105.1 & 101.3 & 147.0 \\
\hline
\end{tabular}

in disasters. From the viewpoint of the maintenance of chronic dialysis, dialysis facilities should take the four disaster management measures proposed by Akatsuka to prevent the interruption of dialysis services due to facility damage. However, the effectiveness of self-help efforts is limited in certain large-scale disasters. It is, therefore, necessary to establish mutual assistance systems for supporting dialysis therapy in local areas through the provision of electricity, water, and fuels such as gasoline and oil. When a disaster of a much larger scale occurs, it is impossible to support dialysis patients by self-help efforts and mutual assistance systems alone. Public help is required in such a disaster.

Dialysis patients are likely to develop cardiovascular events because of physical and psychological stress due to a disaster. They should keep their body and mind at rest and receive an appropriate antihypertensive treatment to reduce the sympathetic nervous system tone. They should also understand in advance the precautions to be taken for daily self-care, communication method in times of disaster, and the availability of dialysis therapy in remote locations.

In the event of a huge disaster that may occur in the future, the measures required to provide dialysis therapy smoothly will be different from those required in GEJED depending on the type of disaster, the extent of damage, the number of dialysis patients living in an affected area, and the occurrence of acute traumatic AKI. However, it is possible to minimize the damage to dialysis therapy facilities caused by disasters if each dialysis facility and each local community now take as many of the measures as possible that are proposed in this report.

\section{Appendix 1}

\section{Recommendations from the survey of dialysis therapy} during GEJED

I. Disaster countermeasures for dialysis facilities, the securing of lifelines, and a support system for supplying resources

1. Dialysis facilities should adopt the basic disaster countermeasures of dialysis rooms to avoid the interruption of dialysis services caused by direct damage to the rooms.
2. Local medical networks should be formed to secure power and water cooperatively among dialysis facilities, rather than depending on the government, if the lifelines are destroyed.

II. Future disaster countermeasures based on the experiences in the affected facilities

1. Previous disaster cases should be analyzed to plan disaster countermeasures considering the characteristics of each local area.

2. Methods of storing medical resources within the local medical network should be examined to ensure the continuity of dialysis services without external support for $48 \mathrm{~h}$ after the occurrence of the disaster.

3. The transfer of patients outside the affected area should be examined if the period of interruption of dialysis services exceeds four days or is expected to last longer depending on the degree of damage to lifelines and facilities.

4. Multiple communication and information transmission methods for emergencies should be prepared.

5. In emergencies, termination of dialysis session should be performed by a regular blood return method because the regular method is reliable and safe. Urgent special release techniques should be adopted depending on the degree of urgency.

6. PD is less vulnerable than other blood purification methods during disasters.

7. The supply of power using private power generation systems and of water using water tanks was highly effective at large facilities, such as disaster base hospitals and local dialysis core hospitals.

8. Local core hospitals for chronic dialysis should be considered separately from anti-disaster center hospitals.

III. Transfer of dialysis patients during disasters and dialysis therapy at alternative facilities

1. If dialysis facilities cannot continue chronic dialysis therapy or cannot secure sufficient amounts of 
medical resources, the dialysis patients should be provided with dialysis services at alternative facilities.

2. The alternative dialysis facilities for the patients should be selected by considering where they live and how they will get there.

3. The transfer of patients should be planned by closely sharing information between the affected and alternative facilities.

4. The patients undergoing dialysis at alternative facilities for a long time should be provided daily life necessities and moral support.

IV. Care of dialysis patients during disasters

1. Dialysis patients should be treated so that they have sufficient time to sleep and they maintain both physical and mental health.

2. The blood pressure and pulse of the dialysis patients should be measured to determine appropriate antihypertensive therapy.

3. Attention should be paid to over-hydration and dehydration of the dialysis patients.

V. Support of human and material resources during disasters

1. An advance group should be organized to collect information on the affected facilities during large-scale disasters.

2. Training programs for volunteers during disasters should be prepared.

3. Dialysis-related material resources should be procured under the support of the government and arranged as packages separate from other medical information in a network specialized for dialysis patients.

VI. Tokyo inland earthquake

1. Disaster countermeasures of dialysis facilities should be planned by considering the features of dialysis facilities in urban areas.

2. A network of dialysis facilities in urban areas should be formed.

3. Disaster countermeasures for a Tokyo Inland Earthquake should be regularly discussed beforehand between dialysis facilities and local governments.

VII. Formation of collaborative systems among local dialysis facilities and governments, regular communications, and patient education

1. A regional information-sharing network for disasters should be formed.
2. The dialysis system to be used during disasters should be discussed between dialysis facilities and local governments.

3. Consensus on the type of minimum necessary information on dialysis patients to be transmitted to alternative facilities for providing dialysis and the transmission method during disasters should be obtained beforehand.

4. Dialysis providers should obtain approval from patients about the possibility of undergoing dialysis at remote alternative facilities during disasters.

\section{Appendix 2}

Members of the Working Group for Survey of Dialysis

Therapy during the Great East Japan Earthquake Disaster

Ikuto Masakane

Yabuki Hospital; Chair of WG; Support area (Yamagata

Prefecture)

Tomoyuki Yamakawa

Shirasagi Hospital; Vice chair of WG; President of Japanese Association of Dialysis Physicians

Toshio Akatsuka

Akatsuka Clinic; Editorial chief of reports

Satoshi Ohmori

Department of Urology, Iwate Medical University,

Affected area (Iwate Prefecture)

Mariko Miyazaki

Division of Nephrology, Endocrinology and Vascular Medicine, Graduate School of Tohoku University, Affected area (Miyagi Prefecture)

Tomoyoshi Kimura

Japan Community Healthcare Organization, Sendai Hospital, Affected area (Miyagi Prefecture)

Masaaki Nakayama

Department of Nephrology, Hypertension, Diabetology, Endocrinology and Metabolism, Fukushima Medical University; Affected area (Fukushima Prefecture)

Kunihiro Yamagata

Department of Nephrology, Clinical Medicine, Graduate School of Comprehensive Human Sciences, University of Tsukuba; Affected area (Ibaraki Prefecture); President of Japanese Society of Nephrology

Junichiro Kazama

Blood Purification Center, Niigata University Medical and Dental Hospital; Support area (Niigata Prefecture)

Naoki Kimata

Department of Blood Purification, Kidney Center, Tokyo Women's Medical University Hospital; Support area (Tokyo)

Shuhei Tozawa

Clinic 198 Sapporo; Support area (Hokkaido)

Tadayuki Kawasaki 


\author{
Mobara Clinic, Maeda Institute of Renal Research, \\ Chair of Japan Association for Clinical Engineers \\ Jun Minakuchi \\ Kawashima Hospital, General Chair of Japanese Society \\ for Dialysis Therapy (at the time of disaster).
}

\section{Acknowledgements}

We greatly thank all dialysis facilities members of JSDT who answered the questions in 2011 JSDT survey for GEJED and the subsequent questions in 2013. We also greatly thank for Japanese Association of Dialysis Physicians (JADP), Japanese Society of Nephrology (JSN), Japan Association for Clinical Engineers (JACE), Japan Academy of Nephrology Nursing (JANN), Japanese Society for Technology of Blood Purification (JSTB), and Medical Technology Association of Japan (MTJAPAN) for composing "Report of Survey of Dialysis Therapy during the Great East Japan Earthquake Disaster: Recommendations for Dialysis Therapy Preparation in Case of Future Disasters" published in 2013 by JSDT.

\section{Funding}

All efforts and costs for the survey for GEJED and making the report was given by JSDT.

\section{Availability of data and materials}

The data and recommendations in the current manuscript are important information for all dialysis facilities, medical staffs, officers working in crisis management and dialysis patients, so all of them are freely available with stating "data from JSDT".

\section{Authors' contributions}

IM wrote the part I and II-6 in the original report and summarized the original huge data from JSDT and made them into the current manuscript. TA wrote the part II-2 in the original report and had a responsibility in editing the original report. TY wrote the part II-1 in the original report and had a responsibility in editing the original report. YT organized the final structure of the JSDT survey for GEJED. RA approved the final proposals for dialysis in a disaster as an executive officer of crisis management in JSDT. TA was an ex-president of JSDT in 2011, who directed the JSDT survey for GEJED. JM was an ex-president of JSDT after TA and directed the process of summarize the JSDT survey for GEJED. $\mathrm{KN}$ is the president of JSDT and gave the final approval for the entire manuscript. All authors read and approve the final manuscript.

\section{Competing interests}

The authors declare that they have no competing interests.

\section{Consent for publication}

Not applicable.

\section{Ethics approval and consent to participate}

The JSDT registry was approved by the ethical committee of JSDT. The original data had been totally anonymized so there are no risks for deteriorating the privacy of the dialysis facilities and the patients.

\section{Author details}

${ }^{1}$ Working Group for Survey of Dialysis Therapy during the Great East Japan Earthquake Disaster, Japanese Society for Dialysis Therapy (JSDT), Tokyo, Japan. ${ }^{2}$ Committee of Renal Data Registry, JSDT, Tokyo, Japan. ${ }^{3}$ Committee of Crisis Management, JSDT, Tokyo, Japan. ${ }^{4}$ Yabuki Hospital, 4-5-5 Shimakita, Yamagata City, Yamagata 990-0885, Japan. ${ }^{5}$ Japanese Association of Dialysis Physicians (JADP), Tokyo, Japan.

Received: 19 June 2016 Accepted: 10 August 2016

Published online: 25 August 2016

\section{References}

1. Causes of death, Great East Japan Earthquake disaster and Police. Retrospective and prospective views (in Japanese). 2011. http://www.npa. go.jp/archive/keibi/syouten/syouten 281 /pdf/ALL.pdf. Accessed 9 Dec 2012.

2. Working Group for Survey of Dialysis Therapy during the Great East Japan Earthquake Disaster, Japanese Society for Dialysis Therapy. Survey of dialysis therapy during the Great East Japan Earthquake Disaster and recommendations for dialysis therapy preparation in case of future disasters (in Japanese). Tokyo: Igakutosho-shuppan Ltd; 2013.

3. Summary of the earthquake and the tsunami. http://www.jma.go.jp/jma/ kishou/books/saigaiji/saigaiji_201101/saigaiji_201101_01.pdf (in Japanese). Accessed 11 Feb 2016

4. Tohoku Pacific Ocean Earthquake (Great East Japan Earthquake) in 2011. 152nd report (in Japanese). http://www.fdma.go.jp/bn/higaihou_new.html. Accessed 15 Feb 2016

5. Report from the National Diet of Japan. Official report of Fukushima nuclear accident independent investigation commission. Tokyo: Tokuma Shoten (in Japanese); 2012

6. White paper on disaster management in Japan 2006. http://www.bousai.go. jp/kaigirep/hakusho/h18/BOUSAI_2006/html/honmon/hm01010101.htm (in Japanese). Accessed 11 Feb 2016.

7. Akatsuka T. Disaster response manual for dialysis rooms (in Japanese). Osaka: Medicus Shuppan Publisher Co. Ltd.; 2008.

8. Haga N, Hata J, Yabe M, Ishibashi K, Takahashi N, Kumagai K, et al. The Great East Japan Earthquake affected the laboratory findings of hemodialysis patients in Fukushima. BMC Nephrol. 2013;14:239.

9. Table 10: number of deaths and mortality rate per 100,000 for main causes of death in different prefectures and 20 major cities. Summary of Monthly Report of Vital Statistics: 2010, Ministry of Health, Labor and Welfare (in Japanese). http://www.mhlw.go.jp/toukei/saikin/hw/jinkou/geppo/nengai10/ toukei10.html. Accessed 11 Feb 2016

10. Table 10: number of deaths and mortality rate per 100,000 for main causes of death in different prefectures and 20 major cities. Summary of Monthly Report of Vital Statistics: 2011, Ministry of Health, Labor and Welfare (in Japanese). http://www.mhlw.go.jp/toukei/saikin/hw/jinkou/geppo/nengai11/ toukei10.html. (Accessed 11 Feb 2016).

11. Sakai R. Situation and prognosis of dialysis patients after Great Hanshin-Awaji Earthquake. J Japanese Assoc Dial Physicians (in Japanese). 1996;1 1:17-20.

12. Kario K. Mechanism of generation of cardiovascular events during disasters and its risk management-from Jichi Medical University Recommendations 2014 (in Japanese). Shinzo. 2007;39:110-9.

13. Tani Y, Nakayama M, Tanaka K, Hayashi Y, Asahi K, Kamata T, et al. Blood pressure elevation in hemodialysis patients after the Great East Japan Earthquake. Hypertens Res. 2014:37(2):139-44.

14. Tanaka K, Nakayama M, Kanno M, Kimura H, Watanabe K, Tani Y, et al. Home blood pressure control after the Great East Japan earthquake in patients on chronic hemodialysis. Ther Apher Dial. 2014;18(2):149-54.
Submit your next manuscript to BioMed Central and we will help you at every step:

- We accept pre-submission inquiries

- Our selector tool helps you to find the most relevant journal

- We provide round the clock customer support

- Convenient online submission

- Thorough peer review

- Inclusion in PubMed and all major indexing services

- Maximum visibility for your research

Submit your manuscript at www.biomedcentral.com/submit 